J. Lake Sci. (湖泊科学) , 2021, 33(6): 1844-1856

DOI 10. 18307/2021. 0618

(C) 2021 by Journal of Lake Sciences

\title{
近三百年来洪泽湖演变过程及其原因分析
}

市宇峥 ${ }^{1,2}$, 薛 滨 ${ }^{1,2 * *}$, 张风菊 2,3

( 1 : 南京信息工程大学地理科学学院,南京 211800)

(2: 中国科学院南京地理与湖泊研究所湖泊与环境国家重点实验室,南京 210008)

(3: 江苏师范大学地理测绘与城乡规划学院,徐州 221116)

摘 要: 洪泽湖是淮河水系中最重要的湖泊之一, 是我国的第四大淡水湖, 它在防洪、灌溉、航运、跨流域调水以及水资源 与水环境保护等方面发挥着重要作用. 过去 300 年来, 由于黄淮关系的演变和人类活动的影响, 洪泽湖水域面积发生剧烈 变化. 研究湖泊水域空间变化有助于认识流域环境变化与人类活动影响. 本文利用 18 世纪初以来的古地图、历史文献资 料及 1981-2016 年期间的 7 期遥感影像数据, 采用遥感和地理信息系统技术相结合的方法, 分析了近 300 年来洪泽湖水 域时空演变过程及其原因. 研究结果表明: 过去 300 年来, 洪泽湖面积总体呈减少趋势, 年际缩减速率为 $0.17 \%$, 且湖域范 围总体表现为由四周向中心缩小的趋势, 其中西南湖域的形态变化最为显著. 具体而言, 清中期以前, 黄河多次夺泗人 淮, 洪泽湖面积变化受黄淮关系、高家堰等水利枢纽的修建以及降水等因素影响. 至清末, 洪泽湖面积由 $3078.78 \mathrm{~km}^{2}$ 下降 至 $2335.73 \mathrm{~km}^{2}$, 共减少 $743.05 \mathrm{~km}^{2}$, 其空间形态也发生了剧烈变化, 该时期黄河改道、降水以及人口增长导致的湖滨围垦 是影响洪泽湖演变的主要原因. 建国以来(1949-2016 年), 洪泽湖面积进一步缩小, 由 $1757.60 \mathrm{~km}^{2}$ 下降至 $1488.43 \mathrm{~km}^{2}$, 共减少了 $269.17 \mathrm{~km}^{2}$, 其中 1995-2000 年间湖泊面积下降最为显著, 共减少了 $281.43 \mathrm{~km}^{2}$, 湖泊动态变化度达到 $2.78 \%$, 该时期自然因素对湖泊水域面积的影响减弱, 而人口增长、围屋及水利工程的修建等人类活动逐渐成为影响洪泽湖演化 的主导因素.

关键词: 洪泽湖; 时空演变;古地图;遥感

\section{The changes of Lake Hongze and its driving forces over the past three hundred years*}

\author{
Bian Yuzheng ${ }^{1,2}$, Xue Bin ${ }^{1,2 * *}$ \& Zhang Fengju ${ }^{2,3}$ \\ (1: School of Geographical Sciences, Nanjing University of Information Science and Technology, Nanjing 211800, P.R.Chi- \\ na) \\ (2: State Key Laboratory of Lake Science and Environment, Nanjing Institute of Geography and Limnology, Chinese Academy \\ of Sciences, Nanjing 210008, P.R.China) \\ (3: School of Geography, Geomatics and Planning, Jiangsu Normal University, Xuzhou 221116, P.R.China)
}

Abstract: Lake Hongze is one of the most important lakes in the Huaihe River water system and the fourth largest freshwater lake in
China. It plays an important role in flood control, irrigation, navigation, inter-basin water transfer, water resources and water envi-
ronment protection. During the past 300 years, the surface area of Lake Hongze has undergone drastic changes due to the changing
relationship between Yellow River and Huai River and the influence of human activities. The study on the spatial change of lake wa-
ter area is helpful to understand the impact of basin environmental change and human activities. Based on ancient maps, historical
documents and 7 phase remote sensing image datas from 1981-2016 since the early 18th century, we analyzed the spatial-temporal
evolution of Lake Hongze over the past 300 years and its driving factors by using a combination of remote sensing and geographic in-
formation system technology in this paper. The results showed that over the past 300 years, the water area of Lake Hongze has pres-
ented a decreasing trend, with an interannual reduction rate of $0.17 \%$. The lake area showed a shrinking trend from the surrounding

* 2021-01-13 收稿;2021-03-01 收修改稿.

国家重点研发计划项目 (2019YFA0607100) 和湖泊与环境国家重点实验室开放研究基金项目(2018SKL003) 联合 资助.

** 通信作者;E-mail: bxue@ niglas.ac.cn. 
to the center, and the most significant change was occurred in the southwest lake area. Specifically, before the middle of Qing Dynasty, the Yellow River rushed in Sishui and Huaihe River many times, and the change of Lake Hongze area was affected by relationship between the Yellow River and the Huaihe River, the construction of Gaojiayan and other water conservancy projects, and precipitation. By the end of the Qing Dynasty, the area of Lake Hongze decreased $743.05 \mathrm{~km}^{2}$ from $3078.78 \mathrm{~km}^{2}$ to $2335.73 \mathrm{~km}^{2}$, and its spatial form also changed dramatically. During this period, the channel diversion of the Yellow River, precipitation and lakeside reclamation caused by population growth were the main reasons for the evolution of Lake Hongze. During 1949-2016, the area of Lake Hongze has been further reduced $269.17 \mathrm{~km}^{2}$ from $1757.60 \mathrm{~km}^{2}$ to $1488.43 \mathrm{~km}^{2}$. The most significant decline trend was found during the period of 1995 and 2000 , with a total decrease area of $281.43 \mathrm{~km}^{2}$ and the lake dynamic change degree reached $2.78 \%$. During this period, natural factors played a relatively small impact on changes of lake area, while human activities such as population growth, reclamation and construction of water conservancy projects became the dominant factor in the evolution of Lake Hongze.

Keywords: Lake Hongze; temporal and spatial evolution; ancient map; remote sensing

湖泊是地球表层系统各圈层间相互作用的连接点, 它的形成与消失、扩张与收缩及其引起的生态环境 演化过程是全球的、区域的和局部的构造和气候事件以及人类活动共同作用的结果 ${ }^{[1]}$. 湖泊作为重要的国 土空间资源, 其动态变化过程对区域生态环境和经济可持续发展具有重要影响 ${ }^{[2]}$. 随着社会经济的不断发 展, 人类活动对湖泊水环境的影响也日益增大. 长期对湖泊资源的不合理开发以及保护管理的缺失, 导致湖 泊面积不断萎缩乃至消亡, 削减了湖泊在饮用水供给、灌溉、航运、调蓄等方面的功能. 因而, 采用各种手段 开展不同时期湖泊时空演变研究,并探索自然和人为因素对湖泊发展演化的综合作用及影响, 对湖泊资源 的合理开发、利用和保护均具有重要意义 ${ }^{[3-5]}$.

湖泊水域面积的动态变化及其影响因素研究历来备受国内外学者关注. 早期, 我国学者多采用历史文 献与地貌沉积物调查资料相结合的历史地貌学方法对湖泊演变规律进行分析复原 ${ }^{[6-12]}$, 然而该方法易受到 自然条件以及历史资料记载方式和内容的约束. 随着遥感技术的日益发展, 其大范围、周期性、实时监测等 特点与传统的历史地貌学方法相比, 具有明显优势 ${ }^{[13-31]}$. 比如殷立琼等 ${ }^{[14]}$ 通过不同时期的 Landsat 卫星遥 感影像, 研究了 1988-2003 年太湖的面积变化状况; Guirguis 等 ${ }^{[15]}$ 利用多时段的假彩色合成图像, 通过主成 分分析法研究了 1983-1991 年埃及 Brullus 湖的动态变化情况; 李宁等 ${ }^{[16]}$ 基于 RS、GIS 技术利用面向对象 分类法提取东北地区湖泊数据, 分析了 2000-2010 年间东北地区湖泊时空变化规律及其驱动因素; Chen 等 ${ }^{[17]}$ 基于地形图与遥感影像, 利用景观形状指数和质心法分析了武汉市东湖近 20 年来的时空变化及其原 因;Leblanc 等 ${ }^{[18]}$ 利用 Meteosat 数据和水文模型, 综合分析非洲乍得湖面积变化及其演变原因; 张国庆 等 ${ }^{[19-20]}$ 利用 ICESat 卫星获取了 2003-2009 年青藏高原湖泊水位数据并分析其水位变化特征, 并借助地形 图与遥感数据, 探讨了 1960-2015 年间中国湖泊面积变化规律及其演变原因. 然而, 目前利用遥感技术研 究湖泊动态变化过程的时间范围大都局限于近几十年以来, 对湖泊百年演化的研究并不多见 ${ }^{[30]}$, 这极大限 制了对历史时期特别是年代际尺度上湖泊时空演变特征的认识.

淮河流域是我国重要的水系之一, 淮河水系的尾问分布着大量淡水湖泊,其中洪泽湖既是该区域面积 最大的湖泊, 也是我国南水北调东线工程输水线路中的重要一环, 其动态变化过程直接关系到南水北调工 程的水质安全, 对周边乃至整个淮河流域的经济与生态可持续发展具有重要意义 ${ }^{[24,27,29,32]}$. 目前关于洪泽湖 的相关研究, 多侧重于利用沉积物反演气候变化 ${ }^{[23,26,33-34]}$ 或简单描述短时间尺度 (如近十年来) 湖泊生态环 境的变化 ${ }^{[24,28-29,31]}$, 而较长时间尺度 (如近百年来) 湖泊水域的时空动态变化研究比较菒乏. 鉴于此,本文基 于古地图、历史文献和遥感影像数据等资料, 采用遥感和地理信息系统技术与方法, 全面分析洪泽湖近三百 年来的时空动态演变过程, 并揭示其演变的主要影响因素, 以期为洪泽湖当前及未来的湖泊管理、远景规划 提供背景资料,并为洪泽湖的科学保护与可持续利用提供参考.

\section{1 研究区概况}

洪泽湖位于江苏省北部、我国南北气候过渡地带 $\left(33^{\circ} 0^{\prime} 36^{\prime \prime} \sim 33^{\circ} 40^{\prime} 12^{\prime \prime} \mathrm{N}, 118^{\circ} 10^{\prime} 12^{\prime \prime} \sim 118^{\circ} 52^{\prime} 12^{\prime \prime} \mathrm{E}\right.$ ), 是 淮河流域典型的大型浅水湖泊, 平均水深仅为 $1.77 \mathrm{~m}$, 其最大长度为 $65 \mathrm{~km}$, 最大宽度为 $55 \mathrm{~km}$ 时, 水域面积 
为 $1576.9 \mathrm{~km}^{2}$, 蓄水量为 $27.9 \times 10^{8} \mathrm{~m}^{3[32]}$. 洪泽湖的主要人湖河流包括淮河、池河、濉河, 其中有 $70 \%$ 以上的 入湖水量来自于淮河, 全湖水域由北部的成子湖湾、西部的溧河湖湾和西南部的淮河湖湾组成 (图 1), 跨洪 泽、淮阴、泗阳、泗洪和盯眙五县. 湖区气候类型为典型亚热带季风气候, 年平均降水量约为 $925 \mathrm{~mm}$, 年平均 气温约为 $14^{\circ} \mathrm{C}^{[34-35]}$. 洪泽湖是由历史上黄河南徙夺淮人海逐渐形成. 自近代以来, 人类活动对湖泊环境的影 响逐渐加深,目前湖泊正面临着面积萎缩及富营养化等一系列生态环境问题.

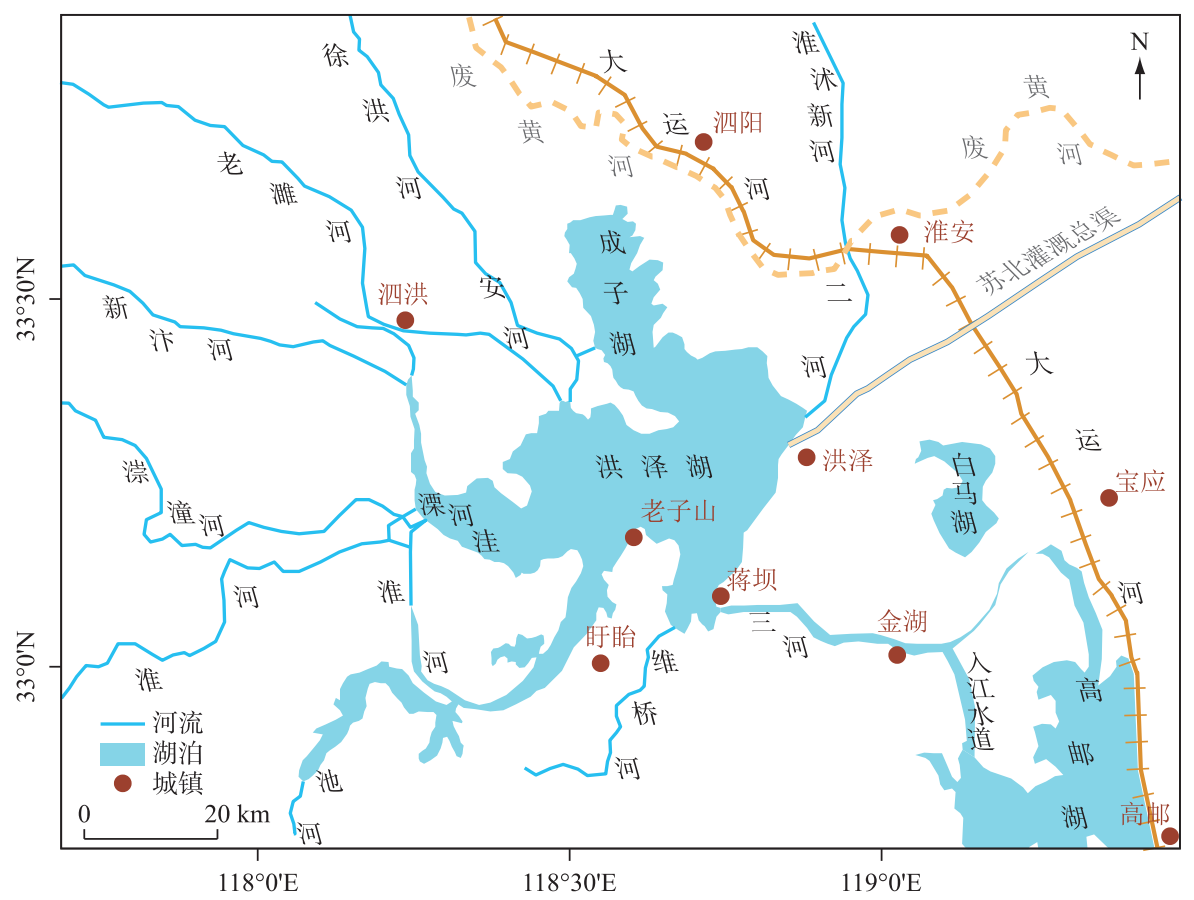

图 1 洪泽湖示意图

Fig.1 Schematic diagram of Lake Hongze

\section{2 数据资料}

由于卫星遥感历史相对较短, 所能提供的反映地面信息的遥感影像时限仅在近 40 年内. 因此, 本文采 用古地图和遥感影像相结合的方法研究洪泽湖长时间尺度的时空演化特征. 历史古地图主要包括无地理参 考、含部分地理信息以及具有较精确地理参考 3 种类型. 其中, 无地理参考历史古地图指的是缺乏空间定位 信息包括比例尺、经纬度等的山水形象画古地图, 与现代地图存在较大差异, 不具备信息提取价值. 含部分 地理信息的历史古地图指的是出现以经纬度测量为主要标志的古地图, 一般以自 1708 年开始由康熙皇帝 组织编著的《皇與全览图》为时间起点 ${ }^{[36]}$. 因此, 基于不同时期古地图的精度差异以及资料的可得性, 本文 主要对 18 世纪初期以来的洪泽湖动态变化过程进行研究, 主要选取公元 18 世纪初康熙年间的《皇與全览 图》、1908 年清末的《大清帝国全图》、民国六年旧地图以及建国后两期现代地图作为地图参考资料. 《皇與 全览图》是在康熙四十七年 (公元 1708 年) 至康熙五十六年间, 在康熙皇帝支持下, 由基督传教士与中方人 员共同进行测绘编制, 采用桑逊投影, 比例尺约为 $1: 140$ 万, 是中国首次以西方现代测绘技术绘制的大范围 的实测地图 ${ }^{[30,36]}$. 本文采用的铜版康熙《皇與全览图》由汪前进、刘若芳主编, 外文出版社 2007 年出版的 《清廷三大实测全图》中收录; 《大清帝国全图》初版为光绪三十一年 (1905 年), 该幅地图采用了西方先进的 编绘技术, 具有较精确的地理参考, 比例尺为 $1: 180$ 万, 全册共 25 幅彩色地图, 由大清帝国图和 24 幅分省图 组成, 本文采用上海商务印书馆 1908 年出版的刊本中江苏省部分; 民国六年旧地图江苏省部分出自商务印 书馆出版《中国新與图》, 该图具有完整的经纬度网格, 比例尺为 $1: 150$ 万. 建国后两幅现代地图分别为 
1949－1951 年、1958-1971 年中国苏北、苏南行署区历史地图, 来源于中国地图出版社出版的《中华人民共 和国行政区划沿革地图集》(1949-1999 年), 地图集主要介绍了新中国 50 年行政区划变迁及现状, 比例尺 为 $1: 260$ 万.

遥感数据方面,在综合考虑各种遥感影像的分辨率、在轨时间和更新周期等因素的基础上,选用 Landsat 系列卫星遥感数据作为洪泽湖水域动态监测的数据源. 该数据源是由美国航空航天局 (NASA) 发射的用来 获取地球表面数据的重要遥感平台, 输出的影像数据为 Geo TIFF 格式, 采样方式为 3 次卷积采样, 地理坐标 系统和地图投影分别为 WGS1984、UTM 投影. 本文使用的 Landsat 系列卫星影像由地理空间数据云 (http:// www.gscloud.cn/) 提供. 考虑到遥感数据的质量或受到云量影响, 以及时相不同可能引起的水域面积变化偶 然误差影响,最终选取 1981-2016 年 4-5 月洪泽湖水位相对稳定且含云量低于 1\% 的 7 期遥感影像数据.

此外, 本文还收集整理了已有的一些文献资料 (研究区自然与人文数据等). 文献资料主要为地方志资 料, 例如《洪泽县志》 ${ }^{[37]}$ 记述了洪泽湖及其周边地区自然和湖泊的社会历史与现状, 作为一部官修志书, 具 有一定的学术性与权威性. 本文选取洪泽湖周边的䀒眙气象站 1957-2016 年间累计日降水量(当日 20 时 至次日 20 时) 和年平均气温数据作为洪泽湖气象数据, 数据来源于中国气象数据网 ( http: //cdc. cma. gov. $\mathrm{cn} /$ ). 人文数据选用淮安市多年以来的人口、农作物播种面积以及人均地区生产总值, 数据主要来源于《淮 阴年鉴》 ${ }^{[38]}$ 、《淮安统计年鉴》 ${ }^{[39]}$ 以及淮安统计局 (http ://data.hatjj.cn/ ).

\section{3 研究方法}

\section{1 古地图( $1708-1971$ 年) 处理方法}

在 Arcgis10.2 环境下,统一采用 WGS1984 地理坐标系, 选取 Albers 地图投影,对 1708-1971 年间 5 幅 古今地图进行配准. 提取古地图中的湖泊形态后对照现代调查资料、地方志和档案文书中相关记载, 对配准 后的地图进行误差校正.

具体而言, 1949、1971 年地图为现代地图, 按照统一的经纬度坐标添加控制点进行地理配准, 提取湖岸 线. 1708-1917 年间《皇與全览图》、《大清帝国全图》和民国六年旧地图为三幅历史地图, 其中民国六年 (1917 年) 旧地图包含较准确的经纬度信息, 因此通过添加经纬网格点作为地理坐标控制点, 对其先进行了 配准. 《皇與全览图》的配准则以年代接近、水域变化幅度相对较小且已配准后的民国六年 (1917 年) 旧地图 为底图, 选取两幅古地图间特征点作为地理控制点, 更新地理配准. 采用统一方法, 对《大清帝国全图》进行 配准. 3 幅古地图配准后, 根据 $30 \mathrm{~m}$ 分辨率数字高程数据结合清代与民国时期地方志等古籍资料进行小幅 度修正. 最后在统一投影坐标系下, 对地图进行矢量化 ${ }^{[30,36]}$,提取各个时期的湖域面积信息.

\section{2 遥感影像(1988-2016 年) 处理方法}

基于对遥感影像的种类与质量、湖泊面积监测的时间跨度、湖泊面积提取的工作量与提取精度等因素 的综合考虑, 本文采取改进的归一化水体指数 (MNDWI) 与人工目视解译相结合的方法对长时间序列的洪泽 湖水域进行遥感提取工作 ${ }^{[40-41]}$. 该方法克服了传统方法中建筑物对水体提取效果的影响, 提高了水体提取 的精度,适用于城市水体的提取. 其计算公式为:

$$
M N D W I=(\text { Green }-M I R) /(\text { Green }+M I R)
$$

式中, Green 为绿波段, MIR 为中红外波段.

具体而言, 本文在 ENVI5.3 环境下,通过水体指数法提取 1981-2016 年间 7 期遥感影像中的洪泽湖水 域变化信息,再通过人工目视解译对提取的湖泊结果进行检核修改, 以提高湖泊提取的精度,完善信息提取. 同时, 利用 Arcgis10.2 平台对归一化处理后的遥感影像中的湖域要素进行矢量化, 获得湖泊面积以及湖泊轮 廓, 并通过 Arcgis10.2 交集取反 ( symmetrical difference) 工具对不同时期洪泽湖矢量图层进行空间叠置分析, 得到不同时间洪泽湖湖域的增减情况. 利用 Excel、SPSS 软件等统计方法, 分析洪泽湖水域面积变化特征及 其演化原因.

此外, 为了进一步分析湖泊动态变化, 本文还引进了湖泊变化动态度 ${ }^{[42]}$ 来直观反映研究区域在一定时 间范围内湖泊面积的变化,其公式为:

$$
K=\left(S_{\mathrm{b}}-S_{\mathrm{a}}\right) / S_{\mathrm{a}} \times 1 / T \times 100 \%
$$


式中, $K$ 为湖泊变化动态度; $S_{\mathrm{a}} S_{\mathrm{b}}$ 分别为研究时段初期及末期的湖泊面积; $T$ 为研究时长, 以年为单位, 此时 $K$ 为研究区域湖泊面积年变化率.

\section{4 结果与分析}

\section{1 洪泽湖演变过程}

4.1.1 洪泽湖空间形态变化特征 1708-2016 年洪泽湖空间形态演变过程如图 2 所示. 历史时期 (1708 年) 的洪泽湖尚未形成固定湖岸线, 与现代洪泽湖形态相比差异显著. 清代晚期至民国初期 (1908-1917 年), 洪泽湖形态与现代相比尽管存在差异, 但轮廓基本趋于一致. 建国以来 (1949-2016 年), 洪泽湖形态变化 较小,仅局部小范围出现湖域增减变化,基本形态已经固定.
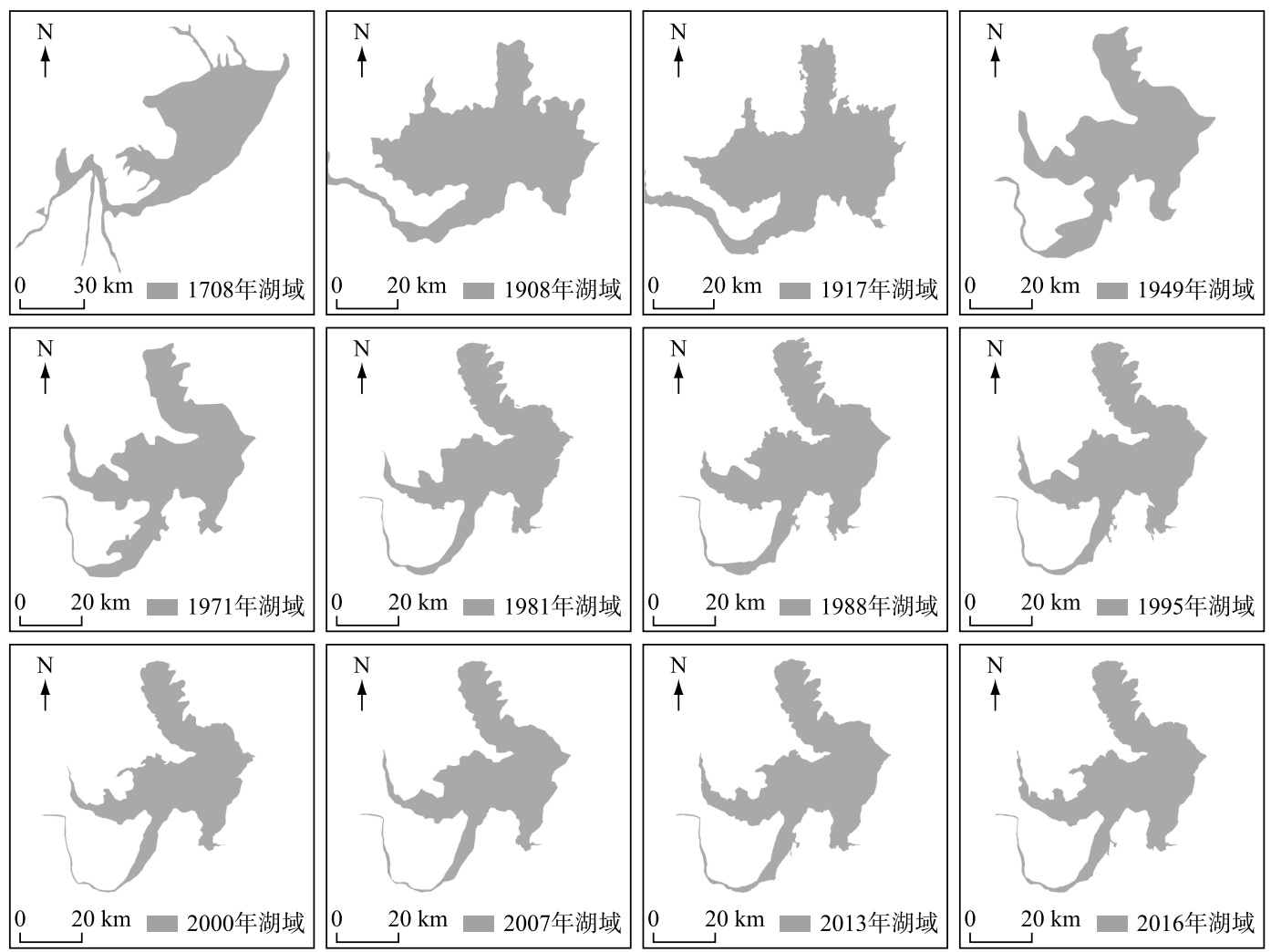

图 2 1708－2016 年洪泽湖形态演变图

Fig. 2 Morphological evolution of Lake Hongze from 1708 to 2016

由于历史时期的洪泽湖形态差异较大且研究年份间的时间间隔较长, 而建国后期的洪泽湖形态相似、 变化较小且研究年份相近, 因此, 分别对历史时期 (1708-1917 年) 的洪泽湖形态进行湖岸线叠置分析, 对建 国后 (1949-2016 年) 的洪泽湖水域进行交集取反分析,得到不同时期洪泽湖形态变化特征(图 3,4).

由图 3 可知, 1708 年洪泽湖总体水域较为宽阔, 轮廓近似梯形; 而 1908 年湖域出现明显收缩, 尤其是北 部水域萎缩显著, 湖泊位置整体向西南方向偏移扩张; 1917 年洪泽湖水域形态与 1908 年近似, 西侧与北侧 湖域面积减小, 湖形趋于稳定.

建国后 (1949-2016 年) 的洪泽湖水域的交集取反分析表明(图 4),1949-1971 年洪泽湖湖域自四周 向中心湖区逐渐缩小; $1970 \mathrm{~s}-1980 \mathrm{~s}$ 湖域进一步减少, 且减幅较大, 尤其在西部和西南部湖区面积大量缩 小; 到了 1980s, 洪泽湖的湖域面积变化则呈现为增加趋势; 但 1980s - 21 世纪初, 洪泽湖的面积再次逐渐缩 小. 对洪泽湖近期 (2013 年与 2016 年) 湖域图像的叠置分析表明, 近年来洪泽湖形态变化主要分布在西部和 
东北部区域,但湖泊总面积变化较小. 总体上, 不同时 期洪泽湖水域面积变化趋势表现为东部区域面积变化 相对平缓,西部区域面积变化幅度相对较大.

4.1.2 洪泽湖面积随时间变化特征 经对不同时期洪 泽湖矢量化图层的几何计算, 得到过去 300 多年来洪 泽湖水域面积变化特征 (图 5). 整体上, 洪泽湖面积呈 萎缩趋势, 面积共减少了 $269.17 \mathrm{~km}^{2}$. 具体而言, 历史 时期 (1708-1917 年), 洪泽湖的湖域面积变化较为显 著, 由 $3078.78 \mathrm{~km}^{2}$ 减少至 $2335.73 \mathrm{~km}^{2}$; 1949 年, 洪泽湖 面积约为 $1500 \mathrm{~km}^{2}$. 其中, 在 $1981-1988$ 年和 19952000 年洪泽湖水域面积变化较明显, 湖泊面积分别增 加了 $187.47 \mathrm{~km}^{2}$ 和减少了 $218.43 \mathrm{~km}^{2}$.

以 1708 年作为湖泊动态变化度初始年份, 其余各 监测年份 (1908-2016 年间) 分别作为末期时间, 对洪 泽湖的湖泊动态变化度进行计算分析. 1708-2016 年, 洪泽湖面积呈减少趋势, 总体动态变化度为 $0.17 \%$, 减 少幅度相对较小. 但在具体时段内, 洪泽湖面积则出现 较大幅度变化. 例如, 1995-2000 年间, 洪泽湖的动态 变化度超过 $2 \%$, 同时 1981-1988 年及 2007-2013 年 的动态变化度也均达到了 $1.5 \%$ (表 1).

\section{2 近 300 年来洪泽湖演化的影响因素分析}

4.2.1 历史时期洪泽湖演化的主要影响因素南宋以 前, 淮河是一条直接人海河流, 排泄较为通畅 ${ }^{[43]}$, 淮河 下游地区曾是历史上商业聚集地. 12 世纪初, 黄河夺泗 人淮, 在决、溢、改道的过程中, 其携带的大量泥沙不断 淤填淮河下游人海河道, 淮河水系遭到破坏, 淮北平原 泛滥成灾.

洪泽湖在黄河夺淮期间 (1128-1855 年), 受黄淮 关系影响, 迅速扩张 ${ }^{[44]}$. 《洪泽湖志》 ${ }^{[37]}$ 曾记载, 明王 朝统治的 267 年中, 洪泽湖地区发生洪涝灾害 111 年, 平均 2.5 年一次. 据《淮系年表》记载, “康熙四十五年 (1706 年), 黄、淮、泗、沂诸水并涨, 七月, 洪泽湖暴涨, 开南北中三坝”. 《行水金鉴》也记载“湖之在泗者有五 十二, 不胜悉载, 州西、北、东三面皆湖”、“每遇夏潦秋 霖, 大水汇注, 害禾稼, 浸城市, 为泗民患”, 表明清代康 熙时期湖面迅速扩张, 导致成子洼、安河洼和溧河洼并 人洪泽湖, 水域不断向西扩展. 另据清康熙时期治水名

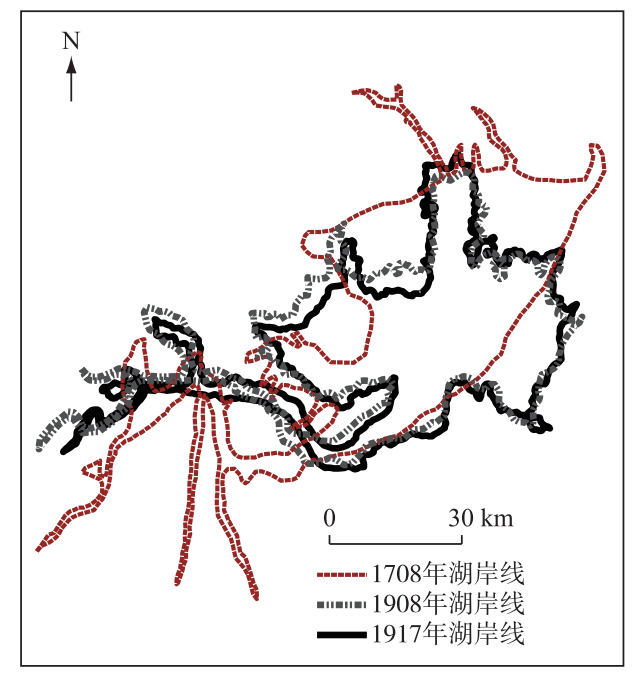

图 3 1708-1917 年洪泽湖空间变化对比

Fig. 3 Comparison of spatial change of Lake Hongze from 1708 to 1917

表 $11708-2016$ 年洪泽湖水域面积及 其动态变化度

Tab.1 The variation of the area and change rate of Lake Hongze from 1708 to 2016

\begin{tabular}{ccccc}
\hline & $\begin{array}{c}\text { 湖泊面积/ } \\
\mathrm{km}^{2}\end{array}$ & $\begin{array}{c}\text { 湖泊面 } \\
\text { 积变化/ } \\
\mathrm{km}^{2}\end{array}$ & $\begin{array}{c}\text { 湖泊动态 } \\
\text { 变化度/ } \\
\%\end{array}$ & $\begin{array}{c}\text { 湖泊总体 } \\
\text { \%变化度/ } \\
\%\end{array}$ \\
\hline 1708 年 & 3078.78 & & & -0.17 \\
1908 年 & 2416.08 & -662.70 & -0.11 & \\
1917 年 & 2335.73 & -80.35 & -0.36 & \\
1949 年 & 1757.60 & -578.13 & -0.77 & \\
1971 年 & 1653.44 & -104.16 & -0.27 & \\
1981 年 1494.72 & -158.72 & -0.96 & \\
1988 年 & 1682.19 & 187.47 & 1.79 & \\
1995 年 & 1571.13 & -111.06 & -0.94 & \\
2000 年 & 1352.70 & -218.43 & -2.78 & \\
2007 年 & 1385.05 & 32.35 & 0.34 & \\
2013 年 & 1516.29 & 131.24 & 1.58 & \\
2016 年 & 1488.43 & -27.86 & -0.61 & \\
\hline
\end{tabular}
臣编修的《治河奏绩书》记载, “洪泽湖在山阳西南九十里, 自东北而西南, 迤逦滂湃于山、清、桃、泗、天长、 高、宝之间. 考之往代三之二皆民田, 自黄河溃决, 全淮隹清, 不得畅流人海, 漫衍四及, 遂为淮风间一巨浸. 其中犹有洪泽村胗胗民居数十, 浮沉于洪涛之中尔. 其广衰数百里”, 可见当时洪泽湖水域扩张剧烈, 甚至淹 没周边古村落. 洪泽湖湖域矢量化图层 (图 2) 提取的该时期湖泊面积达 $3078.78 \mathrm{~km}^{2}$. 清乾隆初年, 洪泽湖湖 区全长 $65 \mathrm{~km}$ 的高家堰水利枢纽逐渐修筑完善, 淮河出清口水量日趋减少, 主流自湖东南或向东穿运河人 海, 或南下高邮、宝应诸湖自运河归江, 淮河大改道趋势开始出现 ${ }^{[45]}$. 清乾隆初年至乾隆五十年间 (17111785 年), 洪泽湖不断淤高, 水位加速抬升, 湖面较前期有所扩 ${ }^{\left[{ }_{1}\right.}{ }^{[4]}$. 随着黄河河道不断淤塞, 黄淮分离趋势 

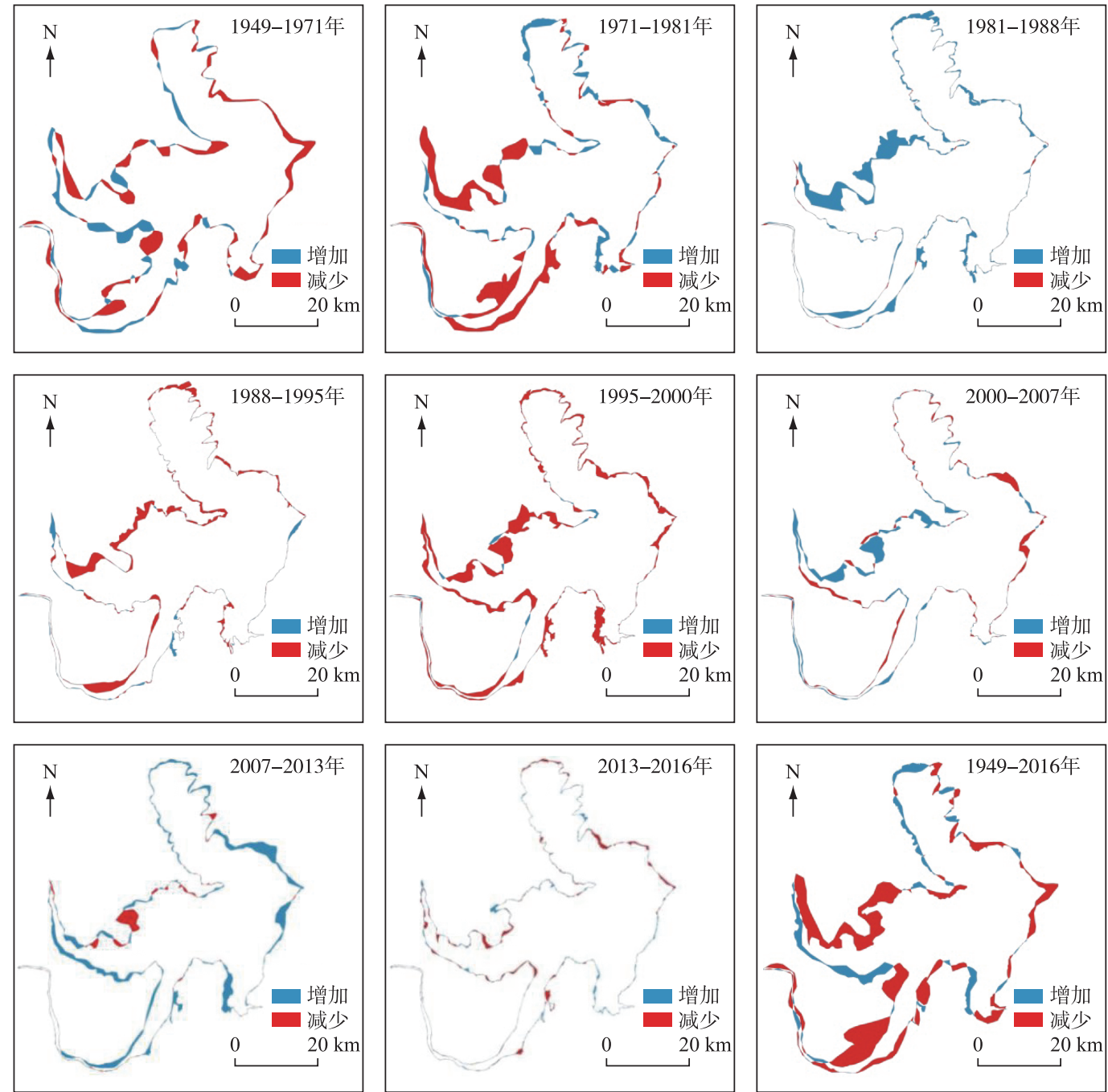

图 4 1949-2016 年间不同时期洪泽湖空间变化

Fig.4 The spatial changes of Lake Hongze in different periods from 1949 to 2016

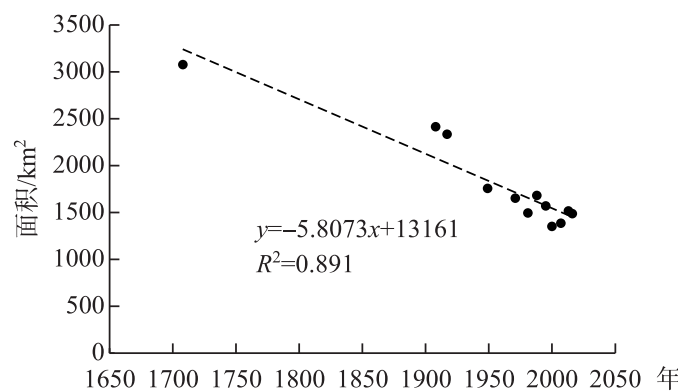

图 5 1708-2016 年洪泽湖面积变化

Fig. 5 The lake area changes of Lake Hongze from 1708 to 2016
加快, 至咸丰元年 (1851 年), 高家堰礼坝决口, 淮河 由此改道自长江人海. 咸丰五年 (1855 年) 黄河改 道, 洪泽湖受黄河威胁减少进人了形成后的稳定时 期 $^{[42,44-48]} .1855$ 年后, 由于黄河北撤, 水源减少, 洪泽 湖水位逐渐下移, 水域面积不断萎缩 ${ }^{[44]}$, “尚不及康 熙时大” ${ }^{[37]} .1708$ 年与 1908 年洪泽湖湖域矢量化图 层对比显示 (图 3 ), 洪泽湖东北部湖区显著萎缩, 面 积由 $3078.78 \mathrm{~km}^{2}$ 减小至 $2416.08 \mathrm{~km}^{2}$ (表 1 ).

人口增长及湖滨围垦, 也加快了洪泽湖的萎缩. 据人口史专家考证, 清咸丰元年 (1851 年) 淮安府人 口约为 329.2 万人, 清同治二十五年 (1865 年) 约为 343.3 万人, 清末 $\left(1910\right.$ 年) 达到 387.9 万人 ${ }^{[49]}$. 清嘉 
庆年间至民国 13 年, 洪泽湖区人口由 30 万人增至 45 万人 ${ }^{[37]}$, 粮食需求也随之日益增加, 围层由此兴盛. 清 咸丰年间 (1851-1861 年), 环湖乡镇 (淮阴县、洪泽县等) 村民及逃荒百姓, 在洪泽湖新滩开荒定居 ${ }^{[37]}$. 洪 泽湖在人为开旺下,水域面积进一步缩小. 上述趋势在 1917 年图层 (图 2) 得到进一步体现,洪泽湖面积较 1908 年共减少 $80.35 \mathrm{~km}^{2}$ (表 1).

淮河流域地处北亚热带和南温带气候过渡带, 干湿变化在一定程度上影响着洪泽湖演变. 历史文献资 料及我国东部季风区干湿、旱涝变化研究数据 ${ }^{[4,50-51]}$ 显示, 淮河流域在过去的 500 多年中, 存在显著的旱涝 异常变化: $1730-1760$ 年流域降水丰沛, 1780-1800 年则相对于湿润期有些偏干, 1840-1870 年略偏干, 即 在清代中后期,淮河流域总体呈湿转旱趋势, 这与 1708-1908 年洪泽湖面积总体呈萎缩趋势具有一致性 (表 1).

综上可知, 历史时期黄淮关系是影响洪泽湖演变的主要因素, 人口增长导致的湖滨围圼以及干湿气候 变化也一定程度上影响着洪泽湖的演变.

4.2.2 建国以来洪泽湖演化的主要影响因素 建国后, 基于洪泽湖面积与多年的年降水量、年平均气温的对 比分析表明 (图 6), 洪泽湖面积演变趋势与同时期降水量和温度变化基本一致. 比如, 1971-1981 年间,洪 泽湖面积由 $1653.44 \mathrm{~km}^{2}$ 减少到 $1494.72 \mathrm{~km}^{2}$ (表 1), 同时期降水量由 $1488.7 \mathrm{~mm}$ 减少至 $785.3 \mathrm{~mm}$, 年平均气 温则从 $14.4^{\circ} \mathrm{C}$ 升至 $14.7^{\circ} \mathrm{C}$; 又如, 表 1 结果显示 $1995-2000$ 年间洪泽湖的动态变化度超过 $2 \%$, 即 $1995-$ 2000 年期间, 洪泽湖面积进一步下降, 而该时期洪泽湖区域降水量也从 $1173.2 \mathrm{~mm}$ 减至 $664.1 \mathrm{~mm}$, 同时期气 温上升了 $0.4^{\circ} \mathrm{C} ; 2010-2016$ 年期间, 洪泽湖面积呈现先增加后下降趋势, 与该时段降水量先增加后减少、年 平均气温先降低后升高基本对应. 然而, 相关性分析显示, 洪泽湖面积变化与年降水量 $(r=0.677, P=0.055)$ 及年平均气温 $(r=-0.580, P=0.102)$ 具有一定的相关性但其相关性并不十分显著, 表明建国以来湖区降水 量及温度变化对洪泽湖面积的影响相对有限.

同时, 相关性分析还表明, 洪泽湖区 (淮安市) 人口数量、人均地区生产总值及粮食作物播种面积与洪泽 湖面积变化呈现显著的相关性 (相关系数分别为 $-0.852 、-0.332 、-0.762, P<0.05$ ), 表明湖区人类活动可能 是湖泊面积演化的主导因素. 1960s 末-1970s 初期, 受到 “以粮为纲” 的政策导向作用加之人口的迅速增 长, 洪泽湖沿岸围湖造田活动加剧, 到了 1990s 开发湖荡更是成为当地居民的致富之道, 这一系列活动导致 湖泊逐渐演变为耕地和居住用地, 水域面积逐渐缩小. 21 世纪以来, 随着生态环境建设重要性逐渐受到重 视, 湖区实施了系列退耕还湖的举措, 导致粮食作物播种面积逐渐减少, 相应的湖泊面积也逐渐呈现增加趋 势(图 7).

新中国成立后, 在政府的高度重视下, 洪泽湖湖区实施了一系列水利设施修建工程. 如 $1950 \mathrm{~s}$ 初期, 在淮 河下游开掘了长达 $168 \mathrm{~km}$ 的苏北灌溉总渠, 并在湖泊东南部兴建了三河闸, 随后在 $1980 \mathrm{~s}$ 修建了高良涧进 水闸等水利设施. 1990s 政府对洪泽湖大堤又进行了 4 次加固 ${ }^{[48,52-53]}$. 尽管上述举措有效提高了洪泽湖下游 地区的防洪作用,但同时也增加了周边的土地利用强度, 造成部分湖区水域面积的减少 ${ }^{[8,53-56]}$.

不同时期, 湖泊演变过程的影响因素有所不同. 历史时期湖泊的演变多由洪涝灾害、泥沙淤积等自然因 素引起, 例如古丹阳湖、硕项湖便是由于泥沙淤积而逐渐消亡 ${ }^{[54-55]}$; 射阳湖也因水患引起泥沙淤积而萎缩为 洼地 ${ }^{[56-57]}$; 包括洪泽湖在内的苏北大运河两侧湖泊的演变, 均受黄河夺淮的影响, 且由南向北逐渐增强 ${ }^{[26]}$. 近代以来, 围湖造田、兴建水利工程、湖周土地利用变化等人类活动成为湖泊演化的主导因素 ${ }^{[14-20]}$; 近年来, 随着湖泊旅游业以及城市化的发展, 原先天然湖岸被改造成水泥岸堤和景观大道, 湖岸线由于水泥固定化, 湖形及其面积变化幅度较小, 趋于稳定 ${ }^{[16,58]}$.

受自然因素和人类活动影响, 不同区域间湖泊有着不同的演变特征 ${ }^{[59]}$. 江苏省湖泊大体呈扩张一萎缩一 稳定演变特征. 苏北大运河两侧湖泊变迁具有一致性 ${ }^{[26]}$, 例如洪泽湖下游的高宝诸湖, 受黄淮关系影响, 洪 泽湖泥沙导致高宝诸湖近 300 来不断萎缩. 将洪泽湖的演变与高宝诸湖的变迁进行对比, 发现二者变化趋 势与时间节点基本同步 ${ }^{[7,12,30,60]}$; 位于苏南地区的太湖, 早期受气候、降水、海面波动以及 “三江” (松江、钱塘 江、浦阳江) 的淤废等自然因素影响而不断扩张 ${ }^{[61-63]}$. 后经宋代至元明清三朝对 “三江” 的大规模整治改造, 其泛溢趋势得以控制 ${ }^{[49]}$. 近年来, 围星和淤积导致众多湖泊消失 ${ }^{[59]}$. 近代洪泽湖、太湖流域等经济发达区域 的湖泊, 大都因滩地围旺、水利建设等强烈的人类经济活动而萎缩 ${ }^{[14,28-29,46,59]}$. 

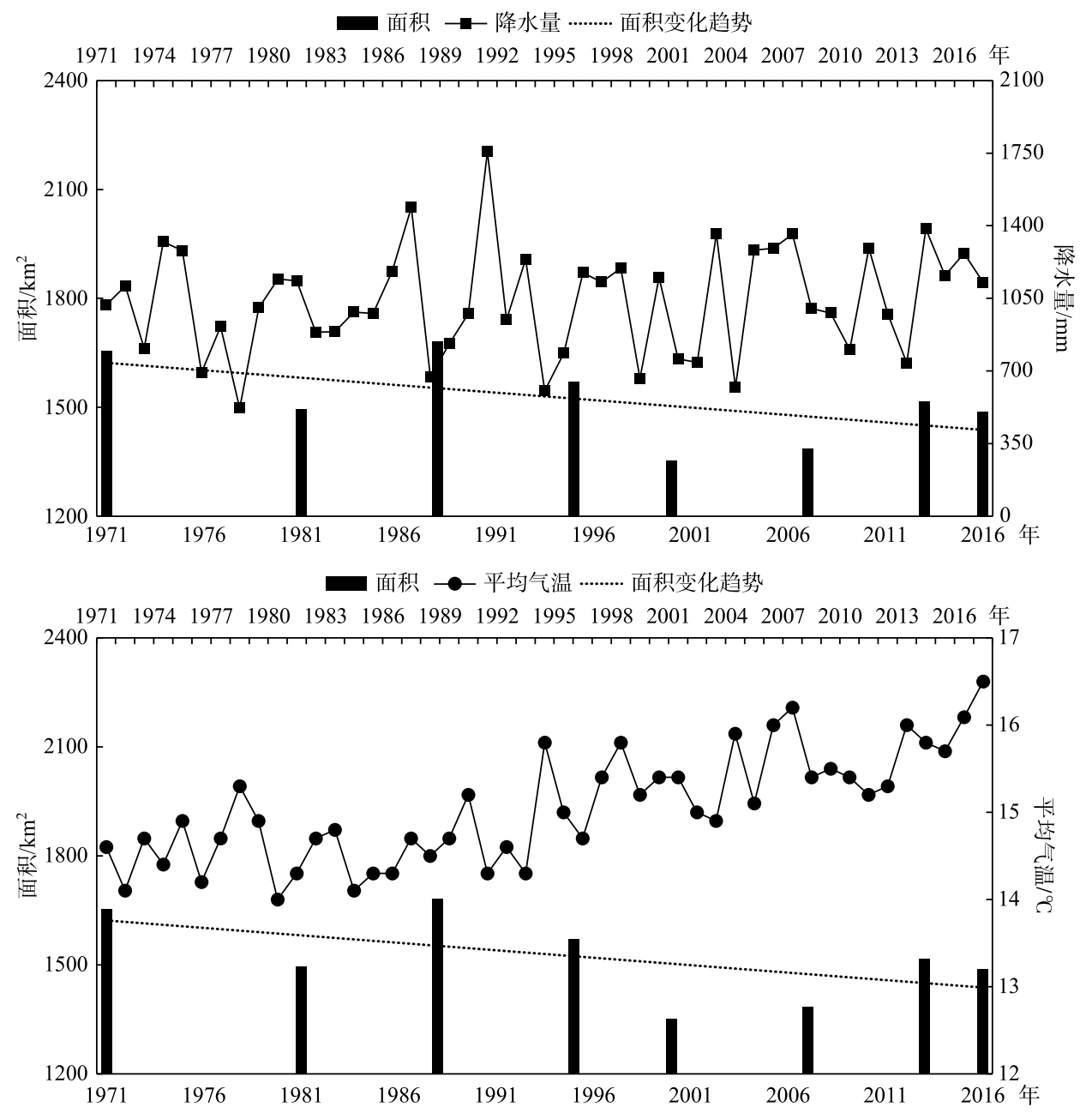

图 6 1971-2016 年洪泽湖面积与年降水量、年平均气温变化

Fig. 6 Changes of Lake Hongze area with annual precipitation and annual average temperature from 1971 to 2016

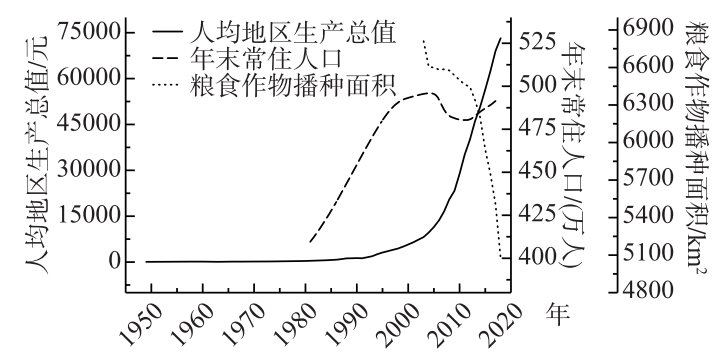

图 7 年末常住人口 ( 1980- 2017 年)、人均地区生产总值( 1949-2018 年)、

粮食作物播种面积 $(2003-2018$ 年) 变化

Fig.7 Changes of population (1980-2017), per capita GDP (1949-2018), sown areas of grain (2003-2018) 


\section{5 结论}

本文基于 ArcGIS 与 ENVI 软件,利用 18 世纪初以来的古地图、1981-2016 年间的遥感影像数据, 结合 历史文献、自然人文等数据资料, 综合分析 300 年来洪泽湖时空演变特征及其演化原因, 主要得出如下 结论:

1) 1708-2016 年间,洪泽湖水域面积随时间不断变化,总体呈下降趋势. 清代至民国时期 ( $1708-1917$ 年),洪泽湖面积变化显著,由 1708 年的 $3078.78 \mathrm{~km}^{2}$ 下降至 1917 年的 $2335.73 \mathrm{~km}^{2}$, 共减少 $743.05 \mathrm{~km}^{2}$,年际 缩减速率为 $0.17 \%$; 建国后, 洪泽湖面积由 1949 年的 $1757.60 \mathrm{~km}^{2}$ 减少至 2016 年的 $1488.43 \mathrm{~km}^{2}$, 共减少了 $269.17 \mathrm{~km}^{2}$. 其中面积最大值出现在 1988 年 $\left(1682.19 \mathrm{~km}^{2}\right)$, 面积最小值出现在 2000 年 $\left(1352.7 \mathrm{~km}^{2}\right)$.

2) 1708-2016 年间,洪泽湖空间形态总体上表现为由四周向湖心缩小的趋势. 1970s $-1908 \mathrm{~s}$ 年间主要 表现为西部和西南部湖区的急剧萎缩, 1980s - 1990s 期间主要表现为西南湖区的扩张, 1990s 湖域再次萎 缩,主要集中于西部, 21 世纪以来洪泽湖变化主要分布集中于湖区西部和东北部,且变化较小.

3) 不同时期,影响洪泽湖水域面积的主导因素各不相同. 清中期以前,黄淮关系以及高家堰等水利枢纽 的修建, 是影响洪泽湖演变的主要因素, 丰沛的降水也进一步导致洪泽湖的扩张; 清末民初, 在湿转干的气 候变化背景下, 黄河改道导致的水源减少以及人口增长引起的湖滨围层, 使洪泽湖面积不断萎缩; 建国后, 湖区人口增长、人类围剭活动以及水利工程的修建等人类活动逐渐成为影响洪泽湖水域面积变化的主导 因素.

\section{6 参考文献}

[ 1 ] Wang SM, Li JR. Late Cenozoic lake deposits of China and environmental outline. J Lake Sci, 1993, 5( 1) : 1-8. DOI: 10. 18307/1993.0101. [王苏民, 李建仁. 中国晚新生代湖泊沉积及其反映的环境概貌. 湖泊科学, 1993, 5(1): 1-8.]

[ 2 ] Jiang LG, Yao ZJ, Liu ZF et al. A review of lake dynamic change research based on remote sensing. Remote Sensing Technology and Application, 2013, 28(5):807-814. [姜丽光, 姚治君, 刘兆飞等. 湖泊动态变化遥感研究综述. 遥感技 术与应用, 2013, 28(5): 807-814.]

[ 3 ] Lu SL, Ouyang NL, Wu BF et al. Lake water volume calculation with time series remote-sensing images. International Journal of Remote Sensing, 2013, 34(22) : 7962-7973. DOI: 10.1080/01431161.2013.827814.

[ 4 ] Huang L, Liu JY, Shao QQ et al. Changing inland lakes responding to climate warming in Northeastern Tibetan Plateau. Climatic Change, 2011, 109(3/4) : 479-502. DOI: 10.1007/s10584-011-0032-x.

[ 5 ] Zhang G, Xie HJ, Yao TD et al. Water balance estimates of ten greatest lakes in China using ICESat and Landsat data. 中 国科学通报: 英文版, 2013, 58(31): 3815-3829.

[ 6 ] Zhang RH. Research on the causes of formation and flood control in the Lake Hongze. Journal of Agricultural Catastropholo$g y, 2012,2(3)$ : 72-75. [张瑞虎. 洪泽湖的成因及其水灾治理. 农业灾害研究, 2012, 2(3) : 72-75.]

[ 7 ] Zhu XH. The history and evolution of Lake Hongze. Journal of Jiangsu Water Resources, 1998, 8(22): 47-48. [ 朱兴华. 洪泽湖成湖历史及演变过程. 江苏水利, 1998, 8(22) : 47-48.]

[ 8 ] Ji XM. A survey of Lake Hongze water records. Journal of Huaiyin Institute of Technology, 2014, 23(6) : 1-6. [季祥猛. 洪泽湖水志考略. 淮阴工学院学报, 2014, 23(6): 1-6.]

[ 9 ] Yang DY, Wang YF. On change of geographic environment and flood damage along the Huaihe river basin during the last 2000 years. J Lake Sci, 1995, 7(1) : 1-7. DOI: 10.18307/1995.0101. [杨达源, 王云飞. 近 2000 年淮河流域地理环 境的变化与洪灾——淮河中游的洪灾与洪泽湖的变化. 湖泊科学, 1995, 7(1): 1-7.]

[10] Jiang JH, Yuan JX, Huang Q. Analysis on the historical floods (1736-1992) in Lake Hongze. J Lake Sci, 1997, 9(3) : 231-236. DOI: 10.18307/1997.0306. [姜加虎, 袁静秀, 黄群. 洪泽湖历史洪水分析(1736- 1992 年). 湖泊科学, $1997,9(3): 231-236$.

[11] Wu BH. The change of river and lake geomorphology in Lixiahe plain after the Yellow River seizes the Huaihe River. Journal of Yangzhou Normal University, 1988, 8(12) : 132-138. DOI: 10.19411/j.1007-824x.1988.z1.027. [吴必虎. 黄河夺 淮后里下河平原河湖地貌的变迁. 扬州师范学报, 1988, 8(12) : 132-138.]

[12] Liao GM. Formation and evolution of the Gaoyou lake, Jiangsu Province. Acta Geographica Sinica, 1992, 47(2) : 139- 
145. [廖高明. 高邮湖的形成和发展. 地理学报, 1992, 47(2): 139-145.]

[13] Harris AR, Mason IM. Lake area measurement using AVHRR-A case study. International Journal of Remote Sensing, 1989, 10(4/5) : 885-895. DOI: 10.1080/01431168908903928.

[14] Yin LQ, Jiang N, Yang YB. Dynamic change of lake Taihu area during the past 15 years based on remote sensing technique. J Lake Sci, 2005, 17(2) : 139-142. DOI: 10.18307/2005.0208. [殷立琼, 江南, 杨英宝. 基于遥感技术的太 湖近 15 年面积动态变化. 湖泊科学, 2005, 17(2): 139-142.]

[15] Guirguis SK, Hassan HM, El-aey ME. Technical note multi-temporal change of Lake Brullus, Egypt, from 1983 to 1991. Remote Sensing, 1996, 17(15) : 2915-2921.

[16] Li N, Liu JP, Wang ZM. Dynamics and driving force of lake changes in northeast China during 2000-2010. J Lake Sci, 2014, 26(4) : 545-551. DOI : 10.18307/2014.0408. [李宁, 刘吉平, 王宗明. 2000-2010 年东北地区湖泊动态变化 及驱动力分析. 湖泊科学, 2014, 26(4) : 545-551.]

[17] Chen KL, Liu XQ, Chen X et al. Spatial characteristics and driving forces of the morphological evolution of East Lake, Wuhan. Journal of Geographical Sciences, 2020, 30(4) : 583-600. DOI: 10.1007/s11442-020-1744-5.

[18 ] Leblanc M, Lemoalle J, Bader JC et al. Thermal remote sensing of water under flooded vegetation: New observations of inundation patterns for the 'Small' Lake Chad. Journal of Hydrology, 2011, 404(1/2) : 87-98. DOI: 10.1016/j.jhydrol. 2011.04.023.

[19] Zhang GQ, Xie HJ, Kang SC et al. Monitoring lake level changes on the Tibetan Plateau using ICESat altimetry data (2003-2009). Remote Sensing of Environment, 2011, 115(7) : 1733-1742. DOI: 10.1016/j.rse.2011.03.005.

[20] Zhang GQ, Yao TD, Chen WF et al. Regional differences of lake evolution across China during 1960s-2015 and its natural and anthropogenic causes. Remote Sensing of Environment, 2019, 221 : 386-404. DOI: 10.1016/j.rse.2018.11.038.

[21] Ma RH, Tang JW. Remote sensing parameters acquisition and algorithm analysis of lake color. Advances in Water Science, 2006, 17(5): 720-726. [马荣华, 唐军武. 湖泊水色遥感参数获取与算法分析. 水科学进展, 2006, 17 (5): 720-726. ]

[22] Ma RH, Yang GS, Duan HT et al. Quantity, area and spatial distribution of lakes in China. Science in China: Series D: Earth Sciences, 2011, 41(3) : 394-401. [马荣华, 杨桂山, 段洪涛等. 中国湖泊的数量、面积与空间分布. 中国科 学: 地球科学, 2011, 41(3): 394-401.]

[23] He HC. Analysis of lake environment in the northern Jiangsu Plain-Taking Lake Hongze as an example[ Dissertation]. Nanjing: Nanjing University, 2002. [何华春. 苏北平原湖泊环境剖析一以洪泽湖为例 [ 学位论文]. 南京: 南京大 学, 2002.]

[24] Liu JN, Liao BH. Determination and evaluation of heavy metal pollution in sediments of Lake Hongze. Journal of Green Science and Technology, 2011, 5(11) : 63-83. [刘嘉妮, 廖柏寒. 洪泽湖沉积物中重金属的污染测定及评价. 绿色科 技, 2011, 5(11): 63-83.]

[25] Ruan RZ, Xia S, Chen Y et al. Change of lake nearby Linhuai town in west bank of Lake Hongze during 1979-2006. Wetland Science, 2012, 10(3) : 344-349. [ 阮仁宗, 夏双, 陈远等. 1979-2006 年洪泽湖西岸临淮镇附近湖泊变化研 究. 湿地科学, 2012, 10(3) : 344-349.

[26] Wang LZ. Comparative study on Lake Evolution in the Jiangsu section of the Grand Canal[Dissertation]. Nanjing: Nanjing University, 2004. [王柳柱. 大运河江苏段湖泊演化对比研究 [学位论文]. 南京 : 南京大学, 2004.]

[27] Gu XM. Distribution and change of lakes and depressions in the central part of the North China Plain in historical period [Dissertation]. Beijing: Peking University, 2008. [顾晓明. 历史时期华北平原中部湖泊洼淀的分布与变迁 [学位论 文]. 北京: 北京大学, 2008.]

[28] Fan YM, He HC, Cui YX et al. The remote sensing analysis on water environment evolution of Lake Hongze. Pollution Control Technology, 2008, 21(6) : 29-33, 84. [范亚民, 何华春, 崔云霞等. 洪泽湖水域的环境演变遥感分析. 污染 防治技术, 2008, 21(6): 29-33, 84.]

[29] Fan YM, He HC, Cui YX et al. Dynamic analysis of water area in the lake of Hongze basin. Resources and Environment in the Yangtze Basin, 2010, 19(12) : 1397-1403. [范亚民, 何华春, 崔云霞等. 淮河中下游洪泽湖水域动态变化研究. 长江流域资源与环境, 2010, 19(12)：1397-1403.]

[30] Yang X, Han ZQ. The change of the Gaobao lakes and its driving forces (1717-2011). Acta Geographica Sinica, 2018, 73(1) : 129-137. DOI : 10.11821/dlxb201801011. [杨霄, 韩昭庆. 1717-2011 年高宝诸湖的演变过程及其原因分 
析. 地理学报, 2018, 73(1): 129-137.]

[31] Huai'an Chronicle Office ed. Huai'an Yearbook. Nanjing Jiangsu People’s Publishing House, 1995-2018. [淮安市志办公 室. 淮安年鉴. 南京: 江苏人民出版社, 1995-2018.]

[32] Wang SM, Dou HS eds. Lakes in China. Beijing: Science Press, 1998: 317-319. [王苏民, 窦鸿身. 中国湖泊志. 北 京: 科学出版社, 1998: 317-319.]

[33] Wan GJ, Xu YF, Li SR et al. Study on hydrochemical components of some lakes and reservoirs in the Yunnan Guizhou Plateau. Environmental Science Series, 1988, 9(3) : 37-51. [万国江, 徐义芳, 李荪蓉等. 云贵高原若干湖泊水库水 化学组分研究. 环境科学丛刊, 1988, 9(3): 37-51.]

[34] Jiang JH ed. Freshwater lakes in the middle and lower reaches of the Yangtze River and Huaihe River. Wuhan: Changjiang Press, 2009. [姜加虎. 江淮中下游淡水湖群. 武汉: 长江出版社, 2009.]

[35] He HC, Ding HY, Zhang ZK et al. Grain size characteristics of Lake Hongze sediments in the middle and lower reaches of the Huaihe River and its significance for sedimentary environment. Acta Geographica Sinica, 2005, 25( 5) : 590-597. [何 华春, 丁海燕, 张振克等. 淮河中下游洪泽湖湖泊沉积物粒度特征及其沉积环境意义. 地理科学, 2005, 25 (5): 590-597.]

[36] Han ZQ. Digitization and significance of Emperor Yu's panorama by Kangxi. Studies in Qing History, 2016, (4) : 53-61. [ 韩昭庆. 康熙《皇與全览图》的数字化及意义. 清史研究, 2016, (4) : 53-61.]

[37] Xun D, Zhang DL eds. Lake Hongze records. Beijing: Local records Publishing House, 2003. [荀德麟, 章大李. 洪泽湖 志. 北京: 方志出版社, 2003.]

[38] National Geomatics Center of China. Map of China and foreign countries in the 20th century. http://ngcc.sbsm.gov.cn/article/gczl/gcjs/201207/20120700001017. shtm. [ 国家地理信息网中心网站. 二十世纪中外大地图. ]

[39] Huai'an Statistics Bureau ed. Huai'an Statistical Yearbook. Beijing: China Statistics Press, 2012-2018. [淮安市统计局. 淮安统计年鉴. 北京: 中国统计出版社, 2012-2018.]

[40] McFeeters SK. The use of the Normalized Difference Water Index (NDWI) in the delineation of open water features. International Journal of Remote Sensing, 1996, 17(7) : 1425-1432. DOI: 10.1080/01431169608948714.

[41] Xu HQ. A study on information extraction of water body with the modified normalized difference water index (MNDWI). Journal of Remote Sensing, 2005, 9 (5) : 589-595. [徐涵秋. 利用改进的归一化差异水体指数 (MNDWI) 提取水体信 息的研究. 遥感学报, 2005, 9(5) : 589-595.]

[42] Fu D, Yue JP. Analysis of water surface area and its change of Lake Hongze based on Landsat Image. Journal of Gansu Science, 2019, 31(2) : 35-39. [伏蝶, 岳建平. 基于 Landsat 影像的洪泽湖水面面积及其变化分析. 甘肃科学学报, $2019,31(2): 35-39$.

[43] Wang YZ, Hu TS, Jiang SM et al eds. Flood disaster and its control in Huaihe River Basin. Beijing: Science Press, 2015 : 25-26. [王友贞, 胡铁松, 蒋尚明等. 淮河流域涝渍灾害及其治理. 北京: 科学出版社, 2015: 25-26.]

[44] Han ZQ ed. Study on the relationship between the Huanghe River and north Huaihe Plain and its evolution. Shanghai: Fudan University Press，1999. [ 韩昭庆. 黄淮关系及其演变过程研究. 上海: 复旦大学出版社, 1999: 117-242.]

[45] Qian M ed. Problems and countermeasures of flood disaster in the middle reaches of Huaihe River. Beijing: China Water Resources and Hydropower Press, 2018: 67-141. [钱敏. 淮河中游洪涝问题与对策. 北京: 中国水利水电出版社, 2018: 67-141.]

[46] Deng H, Xu GB, Duan Y et al. Research progress and Prospect of the relationship between Huaihe River and Lake Hongze. Journal of Water Resources and Water Engineering, 2018, 29(5): 143-147. [邓恒，徐国宾，段宇等. 淮河与洪泽湖 河湖关系研究进展及展望. 水资源与水工程学报, 2018, 29(5):143-147.]

[47] Nanjing Institute of Geography, Chinese Academy of Sciences ed. Jiangsu lake records. Nanjing: Jiangsu Science and Technology Press, 1982. [中国科学院南京地理研究所. 江苏湖泊志. 南京: 江苏科学技术出版社, 1982.]

[48] Peng AY. The construction of Hongzehu dam and its influence. Journal of Huaiyin Normal University, 2012, 34(2) : 189193. [ 彭安玉. 洪泽湖大坝的建成及其影响. 淮阴师范学院学报, 2012, 34(2)：189-193.]

[49] Cao SJ ed. Hist ory of Chinese Population (Book 5). Shanghai: Fudan University Press, 2005: 81-466. [曹树基. 中国人 口史第五卷. 上海: 复旦大学出版社, 2005: 81-466.]

[50] Ge SQ et al eds. Climate change in China. Beijing: Science Press, 2010. [葛全胜等. 中国历朝气候变化. 北京: 科学 出版社, 2010.] 
[51] Zhang DE, Liu CZ, Jiang JM. Reconstruction of dry and wet series and analysis of climatic jump in six regions of eastern China in recent 1000 years. Quaternary Studies, 1997, 17(1): 1-11. [张德二, 刘传志, 江剑民. 中国东部 6 区域近 1000 年干湿序列的重建和气候跃变分析. 第四纪研究, 1997, 17 (1) : 1-11.]

[52] Zhao XX. Research on major water conservancy construction in Northern Jiangsu (1949-1966) [ Dissertation]. Nanjing: Nanjing University, 2012. [赵䈗侠. 苏北地区重大水利建设研究 (1949-1966) [学位论文]. 南京: 南京大 学, 2012.]

[53] Wang Q, Chen JY. Formation and evolution of Lake Hongze and the Huaihe River Mouth along the lake. J Lake Sci, 1999, 11(3) : 237-244. DOI: 10.18307/1999.0308. [王庆, 陈吉余. 洪泽湖和淮河人洪泽湖河口的形成与演化. 湖泊科 学, 1999, 11(3): 237-244.]

[54] Dai JF, Zhao R. An application of remote sensing techniques in the study of palaeo-Danyang Lake evolution. J Lake Sci, 1992, 4(2) : 67-72. DOI: 10.18307/1992.0209. [戴锦芳, 赵锐. 遥感技术在古丹阳湖演变研究中的应用. 湖泊科 学, 1992, 4(2): 67-72.]

[55] Ling S. Changes of land and sea in the Shuoxiang Lake area since Holocene. Marine Science Bulletin, 2003, 22(4) : 4854. [凌申. 全新世以来硕项湖地区的海陆演变. 海洋通报, 2003, 22(4): 48-54.]

[56] Ke CQ. Research on the effects of human activities on the Sheyang Lake. J Lake Sci, 2001, 13(2) : 111-117. DOI: 10. 18307/20010203. [柯长青. 人类活动对射阳湖的影响. 湖泊科学, 2001, 13(2) : 111-117.]

[57] Ling S. Study on models of the changes about Sheyang Lake in historical period. Collections of Essays on Chinese Historical Geography, 2005, 20(3)：73-79. [凌申. 历史时期射阳湖演变模式研究. 中国历史地理论丛, 2005, 20(3): 73-79.]

[58] Yang GS, Ma RH, Zhang L et al. Lake status, major problems and protection strategy in China. J Lake Sci, 2010,22 (6) : 799-810. DOI: 10.18307/2010.0601. [杨桂山, 马荣华, 张路等. 中国湖泊现状及面临的重大问题与保护策 略. 湖泊科学, $2010,22(6): 799-810$.

[59] Li XG, Jiang N, Wang HJ et al. Dynamic changes of lake shorelines morphology in the Taihu basin during the past 30 years. J Lake Sci, 2005, 17(4) : 294-298. DOI: 10.18307/2005.0402. [李新国, 江南, 王红娟等. 近 30 年来太湖流 域湖泊岸线形态动态变化. 湖泊科学, 2005, 17(4) : 294-298.]

[60] Han ZQ. Research on the processes and backgrounds of the changes of the Hongze Lake during historical period. Collections of Essays on Cniness Historical Geography, 1998, (2) : 61-76, 249-250. [韩昭庆. 洪泽湖演变的历史过程及其背景分 析. 中国历史地理论丛, 1998, (2): 61-76, 249-250.]

[61] Zhang XG. The course of the Taihu Lake's evolution in historical period. Journal of Chinese Historical Geography, 2009,24 (1)：5-12. [张修桂. 太湖演变的历史过程. 中国历史地理论丛, 2009, 24(1) : 5-12.]

[62] Hong XQ. Origin and evolution of the Taihu Lake. Marine Geology \& Quaternary Geology, 1991, 11(4) : 87-99. [洪雪 晴. 太湖的形成和演变过程. 海洋地质与第四纪地质, 1991, 11(4) : 87-99.]

[63] Jing CY. Formation and evolution of Taihu Lake. Scientia Geographica Sinica, 1989, 9(4) : 378-385. [景存义. 太湖的 形式与演变. 地理科学, $1989,9(4)$ : 378-385. ] 